\title{
Biological Activities of the Methanolic Extracts of Coccinia indica and Mikania scandens Leaves Available in Bangladesh
}

\author{
Md. Akhtar-E-Ekram, Md. Enamul Haq Sarker, Afrin Priya Talukder, \\ Badhan Sarker, Md. Salah Uddin and Shahriar Zaman
}

\author{
Department of Genetic Engineering and Biotechnology, University of Rajshahi, Rajshahi-6205, Bangladesh
}

(Received: March 25, 2017; Accepted: May 26, 2017; Published (web): June 21, 2017)

\begin{abstract}
Biological activities of the methanolic leaf extracts of Coccinia indica and Mikania scandens were observed through antimicrobial assay, cytotoxic assay and antioxidant activity through DPPH (1,1-diphenyl-2picrylhydrazyl) radical scavenging assay with a comparison of IC $_{50}$ values of extracts with standard antioxidant BHT (butylatedhydroxytoluene). In case of crude extract of Coccinia indica, antimicrobial assay showed that Pseudomonas sp., Escherichia coli were susceptible at a dose of $150 \mu \mathrm{g} / \mathrm{disc}$ out of five tested bacteria. Again, out of five fungi strains, Phytopthora sp., Penicillium notatum, Aspergillus niger were sensitive against $150 \mu \mathrm{g} / \mathrm{disc}$ containing crude extract. In the case of Mikania scandens, antimicrobial assay showed that Pseudomonas sp., Rhizobium for Vigna mongu (RVM), Rhizobium for Cicer arietinum (RCA)were susceptible at a dose of 150 $\mu \mathrm{g} /$ disc, while Escherichia coli was susceptible at only $75 \mu \mathrm{g} / \mathrm{disc}$. Furthermore, out of five fungi strains,

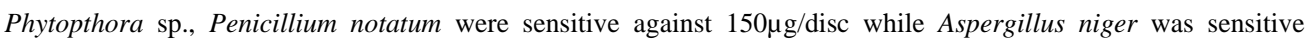
against $100 \mu \mathrm{g} /$ disc and $150 \mu \mathrm{g} /$ disc of $M$. scandens crude extract. The DPPH free radical scavenging activity of $C$. indica leaf extract displayed that it was capable of scavenging the 50\% DPPH at the dose of $130 \mu \mathrm{g} / \mathrm{ml}$ and itindicated that the plant extract had moderate to high antioxidant activity. However, Mikania scandens, the $\mathrm{IC}_{50}$ value was $125 \mu \mathrm{g} / \mathrm{ml}$ which indicated that $M$. scandens leaf extract had strong antioxidant potentialities than the leaf extract of $C$. indica. Cytotoxic assay showed that the methanolic leaf extracts of $C$. indica and $M$. scandens were highly toxic for the aquatic organisms at the concentrations of above 104.60 and $89 \mu \mathrm{g} / \mathrm{ml}$, respectively.
\end{abstract}

Key words: Coccinia indica, Mikania scandens, antimicrobial activity, brine shrimp assay, DPPH (1, 1-diphenyl-2picrylhydrazyl)radical scavenging assay

\section{INTRODUCTION}

Medicinal plant extracts are important reservoirs for modern antimicrobial compound due to the existence of natural bioactive compounds. Coccinia indica, commonly known as 'Telakucha' belongs to the family Cucurbitaceae. ${ }^{1}$ The Cucurbitaceae family is commonly known as gourd, melon and pumpkin family which comprises 125 genera and 960 species. $^{2}$ C. indica is a useful climber tree that is traditionally used for various medicinal purposes in Bangladesh. ${ }^{3}$ Leaves of this plant are also used in Bangladesh as well as India as folk medicine in the form of ailments

Correspondence to: Md. Akhtar-E-Ekram

E-mail: ekram_2012@ru.ac.bd

Dhaka Univ. J. Pharm. Sci. 16(1): 87-93, 2017 (June) herbal for treatment of number of diseases including diabetes, wounds, ulcers, inflammation, fever, asthma, cough and interruptions of skin. ${ }^{4}$ In Bangladesh, the roots are used to treat osteoarthritis and joint pain. ${ }^{5}$

Mikania scandens commonly known as 'Ashamlota'is a species of flowering plant in the Aster family commonly known as Asteraceae or Compositae. $M$. scandens plants have been used in traditional herbal medicine in Bangladesh to treat various ailments including pain, inflammation and some other infectious diseases. ${ }^{6}$ Aqueous leaf extracts of this plant have been used in folk medicine to treat stomach ulcers. Its leaf juice is applied to the affected area of the body to treat wounds and bruises. The 
plant is considered as a rich source of vitamin A and C. The plant also contains vitamin B, mikanin, friedelin, efifriedinol, sesquiterpene, lactone scandenolide, aflavonol and some sesquiterpene dilactones including mikanolide, dihydromikanolide, deoxymikanolide and scandenolide. ${ }^{7}$ Considering their medicinal properties we want to explore the bioactive properties of these two plants to obtain naturally available antimicrobial agents.

\section{MATERIALS AND METHODS}

Plant materials. The leaves of $C$. indica and $M$. scandens were collected from the gardens of Rajshahi University campus during March, 2014. These plants were identified by the taxonomist, Dept. of Botany, University of Rajshahi, Rajshahi-6205, Bangladesh. The voucher specimen number of Coccinia indica and Mikania scandens were 37 and 72, respectively.

Solvents and chemicals. Methanol, DPPH (1, 1diphenyl-2-picrylhydrazyl), BHT (butylatedhydroxytoluene), standard medium (Luria broth liquid, Luria broth agar, potato dextrose agar).

Preparation of extracts. The collected leaves of the plants were washed, unwanted materials were discarded and were dried in room temperature for 30 days. The dried leaves were grinded into small fine particles by a grinder machine, the powder was transferred to an air tight container and kept in a cool and dark place until the screening of their bioactive potentialities. For extraction, about 100 g powder of each plant material (leaves) was taken in $1 \mathrm{~L}$ conical flask. Each sample was soaked in (500-600) $\mathrm{ml}$ of methanol. The conical flasks with its contents were then sealed and kept on orbital shaker for continuous shaking at $150 \mathrm{rpm}$ for 2 days. The mixtures were then filtered through Whatman No.1 filter paper. Using rotary evaporator, the methanolic extract of each plant was evaporated at $(55-60)^{\circ} \mathrm{C}$ temperature and at a rotation speed of (160-180) rpm. After 30 minutes of drying process, a slurry concentration was obtained, which was kept in small vial for further drying. After (20-30) days, the solvents were completely evaporated and the methanol extract of each plant became ready for experiment.
Antimicrobial activity. Antimicrobial screening was conducted according to Clinical and Laboratory Standards Institute (CLSI), USA as a standard of antimicrobial susceptibility test. ${ }^{8}$ It was done against five gram negative bacteria (Rhizobium for Vignamongu-RVM, Rhizobium for Cicerarietinum RCA, Pseudomonas sp., Escherichiacoli and Acetobacter sp.) and six fungal strains (Phytopthora sp., Penicillium notatum, Aspergillus niger, Rhizopus sp., Colletotrichum sp. and Fusarium sp.) at the doses of $10,25,50,75,100$ and $150 \mu \mathrm{g} /$ disc of extracted sample in triplicate. In case of antibacterial activity, 5 mg of each plant leaf extracts (C. indicaand $M$. scandens) were taken in two separate vials and $5 \mathrm{ml}$ of solvent (methanol) were carefully added in each vial. The extracts were then dissolved well in the solvent by inverting the tube. Each of the stock solution (Conc. 1 $\mu \mathrm{g} / \mu \mathrm{l})$ was then labeled and was ready to use for sensitivity test. In this study, Luria broth (LB) liquid and Luria broth (LB) agar medium were used as culture medium for the growth of bacteria. Antibacterial screening was undertaken with disc diffusion method. ${ }^{9,10}$ Kanamycin (10 $\mu \mathrm{g} /$ disc) was used as a standard antibiotic disc.

The extract samples were prepared for antifungal activity test in the same way of antibacterial activity test described before. In this study, potato dextrose agar (PDA) and liquid medium was used to perform the antifungal activity test and for subculture of the test organisms. Antifungal screening was also carried out by the disc diffusion method. Nystatin (10 $\mu \mathrm{g} / \mathrm{disc}$ ) was used as a standard antibiotic disc.

Cytotoxic activity. Cytotoxic activities of two experimental plant samples were conducted at the concentrations of 10, 25, 50, 75, 100 and150 $\mu \mathrm{g} / \mathrm{ml}$ of extracted sample through brine shrimp (A. salina) lethality assay. ${ }^{11}$ Brine shrimp eggs were hatched in simulated seawater to get nauplii. Sample solutions are prepared by dissolving the test materials in precalculated amount of methanol. Ten nauplii were taken in each vial containing $10 \mathrm{ml}$ of simulated seawater. The samples of different concentrations were added to the pre-marked each vial with a micropipette. The assays were performed using three 
replicates. Survivors were counted after 24 hours. These data were processed in a simple program for probit analysis to estimate $\mathrm{LC}_{50}$ values with 95\% confidence intervals for statistically significant comparisons of potencies.

Antioxidant activity. Antioxidant activities of two experimental plant samples were conducted at the concentrations of 50,100 and $150 \mu \mathrm{g} / \mathrm{ml}$ of extracted sample through DPPH free radical scavenging assay. ${ }^{12}$

To prepare the experiment of DPPH scavenging activity test of BHT at different concentrations, at first we took 4 autoclaved test tubes and numbered them as 1, 2, 3 and control. From previously prepared BHT stock solution we took 10,20 and $30 \mu$ solution with the help of micropipette and added to first, second and third test tube respectively, except control test tube. Then, we also added 990, 980, 970 and $1000 \mu \mathrm{l}$ solvent (methanol) in first, second, third and control test tube, respectively. Therefore, the concentrations of the BHT in first three test tubes were 50, 100 and $150 \mu \mathrm{g} / \mathrm{ml}$, respectively. Finally, $1.5 \mathrm{ml}$ of DPPH solution was added to each of the test tube. The test tubes were then incubated at room temperature for 30 minutes in dark to complete the reaction.

After 30 minutes of incubation, absorbance of each solution was measured at $519 \mathrm{~nm}$ using a spectrophotometer against blank. The percentage (\%) of inhibition activity was calculated from the following equation:

\section{$\% I=\left\{\left(A_{0}-A_{1}\right) / A_{0}\right\} X 100$}

where, \% I is percentage of inhibition activity, $A_{0}$ is the absorbance of the control, and $A_{1}$ is the absorbance of the BHT.

Procedure for DPPH radical scavenging assay, activity and $\mathrm{IC}_{50}$ value of the extracts were conducted almost same way as the experimental procedure of BHT. The only difference was that we added extract solution from stock solution of $C$. indica and $M$. scandens leaf extracts instead of BHT solution.

\section{RESULTS AND DISCUSSION}

In antibacterial activity test, Pseudomonas sp., E. coli and Acetobacter sp. were susceptible at the dose of $150 \mu \mathrm{g} /$ disc to $C$. indica leaf extract with $(18.33 \pm$ 1.53) $\mathrm{mm},(18.67 \pm 1.00) \mathrm{mm}$ and $(16.33 \pm 0.58)$ inhibition zones, respectively. However, RVM and RCA were strongly resistant to $C$. indica crude extract (Table1). Shaheen et al. ${ }^{13}$ investigated about the bioactive compounds in fruits of $C$. indica against some pathogenic bacteria. According to Farrukh et al. ${ }^{14}$ water extract of leaves and ethanolic extract of stem showed significant activity against the gram negative bacteria Shigella boydii and Pseudomonas aeruginosa at the dose of $200 \mu \mathrm{g} / \mathrm{disc}$. In our experiment, we also found antibacterial activity of methanolic extract of $C$. indica against pathogenic bacteria. Again, in case of $M$. scandens, RVM, RCA, Pseudomonas sp. and E. coli were susceptible at the dose of $150 \mu \mathrm{g} /$ disc with inhibition zones (22.00 \pm $1.00) \mathrm{mm},(20.00 \pm 1.00) \mathrm{mm},(19.00 \pm 1.00) \mathrm{mm}$, $(23.33 \pm 1.00) \mathrm{mm}$, respectively. It was previously reported by Ghosh et al. ${ }^{15}$ that $M$. scandens leaf extract has antibacterial effect against Bacillus subtilis MTCC 441, Escherichia coli MTCC 739 at the dose of $100 \mu \mathrm{g} / \mathrm{disc}$. But, Acetobacter sp. was resistant in case of $M$. scandens. Overall, $M$. scandens leaf extract possesses stronger antimicrobial activity than that of $C$. indica. All the bacterial strains were strongly susceptible to antibiotic Kanamycin (10 $\mu \mathrm{g} / \mathrm{disc}$ ) and the leaf extracts of both the plants showed nearable effect like this antibiotic.

In case of antifungal assay, we clearly demonstrated that Phytopthora sp., Penicillium notatum and Aspergillus nigerwere susceptible to $C$. indica leaf extract at the dose of $150 \mu \mathrm{g} /$ disc with $(18.33 \pm 1.53) \mathrm{mm},(19.67 \pm 2.08) \mathrm{mm},(18.67 \pm$ 1.15) $\mathrm{mm}$ inhibition zones, respectively. It was reported that aqueous and ethanol extract of $C$. indica leaves showed potent antifungal activity against Aspergillus niger ATCC 1204 and Candida albicans at the dose of $100 \mu \mathrm{g} / \mathrm{disc}^{16}$ Another investigation reported that Aspergillus flavus, Candida albicans, Mucor indicus were more sensitive to $C$. indica leaf extract at the dose of 100 and $150 \mu \mathrm{g} /$ disc. ${ }^{17}$ In case of both $C$. indica and $M$. scandens plant extracts, Colletotrichum sp. was intermediately resistant and remaining other two fungal species Rhizopus sp. and Fusarium sp. were strongly resistant at the dose of 
$150 \mu \mathrm{g} /$ disc. In our current study, we also obtained that Phytopthora sp., Penicillium notatum and Aspergillus niger were susceptible to $M$. scandens crude extract at the dose of $150 \mu \mathrm{g} /$ disc with $(18.33 \pm$ $0.58) \mathrm{mm},(18.67 \pm 1.53) \mathrm{mm},(21.00 \pm 1.00) \mathrm{mm}$ inhibition zones, respectively. It was also reported by Siddiqui et al. ${ }^{18}$ that essential oil of $M$. scandens leaf has antifungal effect against Pythium graminicola, Fusarium oxysporum at the dose of $125 \mu \mathrm{g} /$ disc and
Tricoderma harzianum was susceptible at the dose of $200 \mu \mathrm{g} /$ disc. All the fungal strains were strongly susceptible to standard antibiotic Nystatin (10 $\mu \mathrm{g} /$ disc) except Rhizopus sp. and Fusarium sp. So, this current experiment showed similar result with previous records of the antifungal activity and also indicates promising antifungal effect for both plant extracts against four pathogenic fungal strains.

Table 1. Antimicrobial activity of $C$. indica and $M$. scandens methanolic extracts.

\begin{tabular}{|c|c|c|c|}
\hline \multirow[t]{2}{*}{ Name of bacteria } & \multicolumn{3}{|c|}{ Diameter of Zone of inhibition (mm) } \\
\hline & C. indica extract (150 $\mu \mathrm{g} / \mathrm{disc})$ & M. scandens $(150 \mu \mathrm{g} / \mathrm{disc})$ & $\begin{array}{l}\text { Kanamycin } \\
(10 \mu g / \text { disc })\end{array}$ \\
\hline RVM & $8.67 \pm 0.58$ & $22.00 \pm 1.00$ & $30.67 \pm 1.15$ \\
\hline RCA & $8.33 \pm 0.58$ & $20.00 \pm 1.00$ & $28.00 \pm 1.00$ \\
\hline Pseudomonas sp. & $18.33 \pm 1.53$ & $19.00 \pm 1.00$ & $31.33 \pm 1.15$ \\
\hline Escherichia coli & $18.67 \pm 1.00$ & $23.33 \pm 1.00$ & $30.33 \pm 2.52$ \\
\hline Acetobacter sp. & $16.33 \pm 0.58$ & $6.00 \pm 0$ & $19 \pm 1.00$ \\
\hline Fungi & & & Nystatin $(10 \mu \mathrm{g} / \mathrm{disc})$ \\
\hline Phytopthora sp. & $18.33 \pm 1.53$ & $18.33 \pm 0.58$ & $30.67 \pm 1.15$ \\
\hline Penicillium notatum & $19.67 \pm 2.08$ & $18.67 \pm 1.53$ & $24.33 \pm 0.58$ \\
\hline Aspergillus niger & $18.67 \pm 1.15$ & $21.00 \pm 1.00$ & $29.67 \pm 0.58$ \\
\hline Rhizopus sp. & $0 \pm 0$ & $0 \pm 0$ & $0 \pm 0$ \\
\hline Colletotrichum sp. & $14 \pm 1.00$ & $11.67 \pm 0.58$ & $22.67 \pm 0.58$ \\
\hline Fusarium sp. & $0 \pm 0$ & $0 \pm 0$ & $0 \pm 0$ \\
\hline
\end{tabular}

The present study investigated the cytotoxic effect of $C$. indica leaf extracts at six concentrations of 10, 25, 50, 75, 100 and $150 \mu \mathrm{g} / \mathrm{ml}$. For C. indica leaf extract, it was found that $\mathrm{LC}_{50}$ was $104.60 \mu \mathrm{g} / \mathrm{ml}$ and the regression equation was $\mathrm{Y}=1.957371+$ 1.5066X, while the $95 \%$ confidence limits were 71.90 to $152.17 \mu \mathrm{g} / \mathrm{ml}$ for the of exposure (Table 2). C. indica leaf extract showed ability to kill the $50 \%$ of brine shrimp at the concentration 104.60 $\mu \mathrm{g} / \mathrm{ml}$. So, it was clear that $C$. indica leaf extract showed $50 \%$ toxicity against aquatic organism at the concentration of $104.60 \mu \mathrm{g} / \mathrm{ml}$.

The present study revealed the cytotoxic effect of M. scandens leaf extract at six different concentrations of 10, 25, 50, 75, 100 and $150 \mu \mathrm{g} / \mathrm{ml}$. For $M$. Scandens leaf extract, we found that the $\mathrm{LC}_{50}$ is $89 \mu \mathrm{g} / \mathrm{ml}$ and the regression equation was $\mathrm{Y}=$ $2.235752+1.417984 \mathrm{X}$, while the $95 \%$ confidence limits were 62.03 to $127.71 \mu \mathrm{g} / \mathrm{ml}$ for the 24 hours of exposure (Table 2).

Therefore, we concluded that $M$. scandens leaf extract was responsible of $50 \%$ mortality of $A$. salina at the concentration of $89 \mu \mathrm{g} / \mathrm{ml}$.

The cytotoxicity of plant material would indicate the presence of bioactive compounds in plant extract and whether the plant extract has toxicity at cell level of aquatic organism. ${ }^{19}$ According to ample investigation by various researchers the ethanolic root extract of $C$. indica showed $50 \%$ mortality $\left(\mathrm{LC}_{50}\right)$ of aquatic organism (A. salina) at the concentration of $125 \mu \mathrm{g} / \mathrm{ml} .{ }^{20}$ It was also reported that ethanolic leaf extract of $C$. indica showed $50 \%$ mortality $\left(\mathrm{LC}_{50}\right)$ of $A$. salina at the concentration of $95 \mu \mathrm{g} / \mathrm{ml}$. In case of M. scandens, it was depicted that its same genera, the ethanolic extract of $M$. cordata showed $50 \%$ mortality of aquatic organism (A. 
salina) at the concentration of $90 \mu \mathrm{g} / \mathrm{ml}^{21}$ Dewi et cordata showed toxicity with $\mathrm{LC}_{50}$ at $40.43 \mu \mathrm{g} / \mathrm{ml}$. $a l^{22}$ confirmed that the ethanolic root extract of $M$.

Table 2. $\mathrm{LC}_{50}, 95 \%$ confidence limits, regression equation and Chi-square value of cytotoxicity of $C$. indica and $M$. scandens leaf extracts against $A$. salina with 24 hours of exposure.

\begin{tabular}{|c|c|c|c|c|c|}
\hline \multirow[t]{2}{*}{ Plant sample } & \multirow{2}{*}{$\begin{array}{c}\mathrm{LC}_{50} \\
\text { value }(\mu \mathrm{g} / \mathrm{ml})\end{array}$} & \multicolumn{2}{|c|}{ 95\% confidence limits } & \multirow[t]{2}{*}{ Regression equation } & \multirow{2}{*}{$\begin{array}{l}\text { Chi-square value } \\
\text { (df) }\end{array}$} \\
\hline & & Upper & Lower & & \\
\hline C. indica & 104.60 & 152.17 & 71.90 & $\mathrm{Y}=1.957371+1.5066 \mathrm{X}$ & $0.3309(4)$ \\
\hline M. scandens & 89 & 127.71 & 62.03 & $\mathrm{Y}=2.235752+1.417984 \mathrm{X}$ & $0.3522(4)$ \\
\hline
\end{tabular}

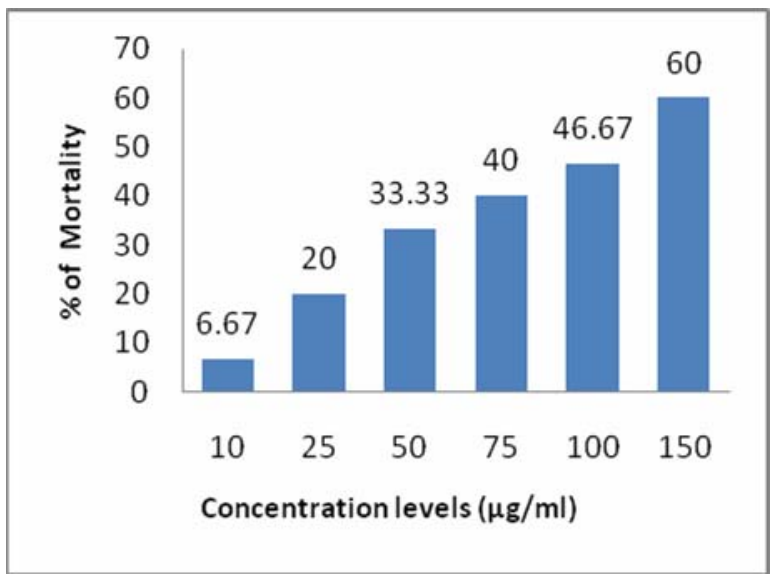

Figure 1.Percent of mortality of brine shrimp by C. indica.

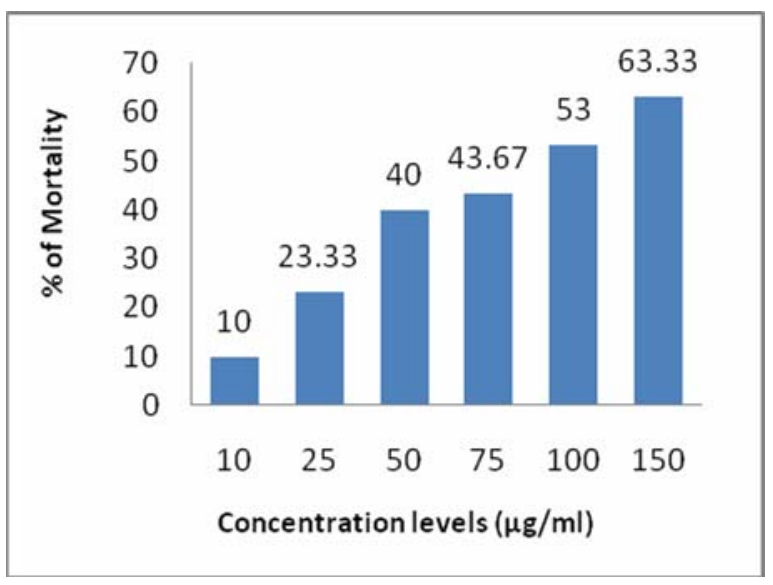

Figure 2. Percent of mortality of brine shrimp by M. scandens.

In our present study we revealed that the leaf extract of $C$. indica and $M$. scandens showed toxicity to A. salina with $\mathrm{LC}_{50}$ at 104.60 and $89 \mu \mathrm{g} / \mathrm{ml}$, respectively. So, our findings showed similarity with previous researcher and indicated that the methanolic leaf extract of $C$. indica and $M$. scandens are promising for the presence of bioactive compounds and are highly toxic for the aquatic organism at the concentration of above $104.60 \mu \mathrm{g} / \mathrm{ml}$ and $89 \mu \mathrm{g} / \mathrm{ml}$ concentrations, respectively.

The present study explored the antioxidant effect (DPPH free radical scavenging activity) of BHT standard at three concentrations 50 and 100 and 150 $\mu \mathrm{g} / \mathrm{ml}$. The DPPH free radical scavenging activities of BHT were found as $63.68 \%$, $88.50 \%$ and $95.83 \%$ at the concentrations of 50 and 100 and $150 \mu \mathrm{g} / \mathrm{ml}$, respectively with $\mathrm{IC}_{50}$ value of $36 \mu \mathrm{g} / \mathrm{ml}$ (Table 3 ). So, BHT exhibited high antioxidant activity with $\mathrm{IC}_{50}$ value of $36 \mu \mathrm{g} / \mathrm{ml}$.

The present study also revealed the antioxidant effect (DPPH free radical scavenging activity) of $C$. indica leaf extract among the three doses (50, 100 and $150 \mu \mathrm{g} / \mathrm{ml}$ ). The DPPH free radical scavenging activity of $C$. indica leaf extract were found as 26.84 , 43.42 and $54.36 \%$ at the doses of 50, 100 and 150 $\mu \mathrm{g} / \mathrm{ml}$, respectively, with $\mathrm{IC}_{50}$ value of $130 \mu \mathrm{g} / \mathrm{ml}$ (Table 3). So, we can say that this plant extract had moderate to high antioxidant effect although this effect was not nearable to the synthetic antioxidant (BHT). On the otherhand, we recorded the antioxidant effect of $M$. scandens leaf extract among three concentrations (50, 100 and $150 \mu \mathrm{g} / \mathrm{ml}$ ). The antioxidant activities of $M$. scandens leaf extract were found as 39.96, 45.38 and $54.82 \%$ at the concentrations of 50, 100 and $150 \mu \mathrm{g} / \mathrm{ml}$, respectively, with $\mathrm{IC}_{50}$ value of $125 \mu \mathrm{g} / \mathrm{ml}$ (Table 3). So, it was proved that $M$. scandens leaf extract had strong antioxidant potentialities than the leaf extract of $C$. indica.

Ashwini et al. ${ }^{23}$ demonstrated that methanolic fruit extract of $C$. indica has potent antioxidant 
activity with $\mathrm{IC}_{50}$ value $140 \mu \mathrm{g} / \mathrm{ml}$. Another scientific research demonstrated that $C$. indica root extract has high antioxidant activity with $\mathrm{IC}_{50}$ value $135 \mu \mathrm{g} / \mathrm{ml}^{24}$ It was also assessed that the hydromethanolic leaf extract of $M$. scandens has effective antioxidant activity with $\mathrm{IC}_{50}$ value $130 \mu \mathrm{g} / \mathrm{ml}^{25}$ We also found similar results in case of $C$. indica and $M$. scandens leaf extracts with the $\mathrm{IC}_{50}$ value $130 \mu \mathrm{g} / \mathrm{ml}$ and $125 \mu \mathrm{g} / \mathrm{ml}$, respectively. Our findings indicated that the leaf extracts of $C$. indica and $M$. scandens had enormous potentiality as a natural source of antioxidant. The positive responses obtained in the assays suggest that the extracts may contain important biologically active compounds. Therefore, we confirmed that if both the plant leaf extracts are used as alternative of agrochemical, these will not pose cancer or oxidative damage on human body because of their potent antioxidant efficiency.

Table 3. Percentage of scavenging of DPPH with $\mathrm{IC}_{50}$ value of standard antioxidant (BHT), C. indica and M. scandens leaf extracts.

\begin{tabular}{|c|c|c|c|c|c|c|c|}
\hline \multirow{2}{*}{$\begin{array}{l}\text { Name of } \\
\text { sample }\end{array}$} & \multirow{2}{*}{$\begin{array}{l}\text { Conc. } \\
(\mu \mathrm{g} / \mathrm{ml})\end{array}$} & \multicolumn{3}{|c|}{ Absorbance } & \multirow{2}{*}{$\begin{array}{c}\text { Absorbance Mean } \pm \\
\text { STD }\end{array}$} & \multirow{2}{*}{$\begin{array}{l}\text { \% of DPPH } \\
\text { Scavenging }\end{array}$} & \multirow{2}{*}{$\begin{array}{c}\mathrm{IC}_{50} \\
(\mu \mathrm{g} / \mathrm{ml})\end{array}$} \\
\hline & & a & b & C & & & \\
\hline \multirow{3}{*}{ BHT } & 50 & 0.288 & 0.274 & 0.281 & $0.281 \pm 0.007$ & 63.97 & \multirow{3}{*}{36} \\
\hline & 100 & 0.094 & 0.092 & 0.090 & $0.092 \pm 0.002$ & 88.50 & \\
\hline & 150 & 0.033 & 0.034 & 0.030 & $0.356 \pm 0.001$ & 95.83 & \\
\hline \multirow{3}{*}{ C. indica } & 50 & 0.542 & 0.599 & 0.571 & $0.570 \pm 0.028$ & 26.84 & \multirow{3}{*}{130} \\
\hline & 100 & 0.425 & 0.458 & 0.441 & $0.441 \pm 0.016$ & 43.42 & \\
\hline & 150 & 0.363 & 0.349 & 0.356 & $0.356 \pm 0.007$ & 54.36 & \\
\hline \multirow{3}{*}{ M. scandens } & 50 & 0.475 & 0.462 & 0.468 & $0.468 \pm 0.006$ & 39.96 & \multirow{3}{*}{125} \\
\hline & 100 & 0.433 & 0.419 & 0.426 & $0.426 \pm 0.007$ & 45.38 & \\
\hline & 150 & 0.319 & 0.370 & 0.320 & $0.319 \pm 0.001$ & 59.10 & \\
\hline
\end{tabular}

\section{ACKNOWLEDGEMENT}

Authors are highly grateful to the Authority of Microbiology Lab, Department of Genetic Engineering and Biotechnology, Rajshahi University for purveying all the necessities to fulfill the research work.

\section{REFERENCES}

1. Wasantwisut, E. and Viriyapanich, T. 2003. Ivy gourd (Cocciniagrandis Voigt, Cocciniacordifolia, Cocciniaindica) in human nutrition and traditional applications. World Rev. Nutr. and Diete. 91, 60-66.

2. Rao, G. M., Rao, C. and Mehrotra, S. 2003. Hepatoprotective effect of Cocciniaindica against CCI4 induced hepatotoxicity. Nat. Prod. Sci. 9, 13-17.

3. Azad Khan, A. K., Akhtar, S. andMahtab, H. 1979. Coccinia indicain the treatment of patients with diabetes mellitus. Bangladesh Med. Res. Coun. Bull. 5, 60-6.

4. Zakaria, D. M., Islam, M., Anisuzzaman, S. M., Kundu, S. K., Khan, M. S. and Begum, A. A. 2011. Ethnomedicinal survey of medicinal plants used by folk medical practitioners in four different villages of Gazipur district, Bangladesh. Adv. Nat. and Appl. Sci. 5, 458-465.
5. Hussain, A., Wahab, S., Zarin, I. and Hussain, M. S. 2010. Antibacterial activity of the Leaves of Coccinia indica (W. and A) wof India. Adv. Biol. Res. 4, 241-248.

6. Uddin N. S. 2006. Traditional Uses of Ethnomedicinal Plants of the Chittagong Hill Tracts. first edition, Bangladesh National Herbarium, Dhaka, Bangladesh, pp. 679.

7. Bohlmann, F., Adler, A., Jakupovic, J., King, R. M. and Robinson, H. 1982. A dimeric germacranolide and other sesquiterpene lactones from Mikania species. Phytochemistry. 21, 1349-1355.

8. Cockerill, F. R. 2011. Performance standards for antimicrobial susceptibility testing: twenty-first informational supplement. Clinical and Laboratory Standards Institute (CLSI), USA.

9. Bauer, A. W., Kirby, W. M., Sherris, J. C. and Turek, M. 1966. Antibiotic Susceptibility Testing by a standardized single Disk method. Am. J. Clin. Pathol. 45, 493-496.

10. Barry, A. L. 1976. Principle and Practice of Microbiology. Lea and Fabager. Philadelphia, pp. 36.

11. Ramesh, P. and Okigbo, R. N. 2008. Effects of plants and medicinal plant combinations as anti-infectives. Afirican $J$. Pharm. and Pharmacol. 2, 130-135.

12. Brand-williams, W., Cuvelier, M. E. and Berset, C. 1995. Use of free radical method to evaluate antioxidant activity. Lebensmittel Wissenschaft und Technol. 28, 25-30. 
13. Shaheen, S. Z., Bolla, K., Vasu, K. and Charya, M. S. 2009. Antimicrobial activity of the fruit extracts of Cocciniaindica. African J. Biotechnol. 8, 7073-7076.

14. Farrukh, U., Shareef, H., Mahmud, S., Ali, S. A. and Rizwani, G. H. 2008. Antibacterial activities of Cocciniagrandis L. Pakistan J. Bot. 40, 1259-1262.

15. Ghosh, A., Das, B. K., Roy, A., Mandal, B. and Chandra, G. 2008. Antibacterial activity of some medicinal plant extracts. J. Nat. Med. 62, 259-262.

16. Pal, P., Chakraborty, S., Samanta, A., Bhattacharya, B. and Samanta, M. 2010. Evaluation of Antifungal and Antibacterial Activities of the Plant Cocciniagrandis (L.) Voigt. (FamilyCucurbitaceae). J. Phytology. 2, 52-57.

17. Satheesh, L. S. and Murugan, K. 2011. Antimicrobial activity of protease inhibitor from leaves of Cocciniagrandis $(L$.) Voigt. Indian J. Expt. Biol. 49, 366-374.

18. Siddiqui, S. A., Islam, R., Jamal, A. H. M., Parvin, T. and Rahman, A. 2013. Chemical composition and antifungal properties of the essential oil and various extracts of Mikania scandens (L.) Willd. Arabian J. Chem. 17, 106.

19. Martin-Cordero, C., Saenz, M. T., Ayuso, M. J. and Caviedes, M. A. 1995. Cytotoxic activity of Retamasphaerocarpa. Fitoterapia. 66, 495-498.
20. Hasanuzzaman, M., Sayeed, M. S. B., Islam, M. S., Sarwar, M. S., Mizanur, M., Moghal, R. and Islam, M. S. 2013. Preliminary antimicrobial activity and cytotoxicity of plant extract (roots) of Cocciniagrandis (Family: cucurbitaceae). Intl. J. Pharma. Sci. and Res. 4, 1466.

21. Al Nayeem, A., Khatun, A., Rahman, M. S. and Rahman, M. 2011. Evaluation of phytochemical and pharmacological properties of Mikaniacordata (Asteraceae) leaves. $J$. Pharmacognosy and Phytotherapy. 3, 20-20.

22. Dewi, K. S. and Ridwanuloh, J. 2011. Phytochemical screening, antibacterial and cytotoxic activity of Mikaniacordata extracts. J. Nat. Med. 56, 232-234.

23. Ashwini, M., Lather, N., Bole, S., Vedamutrhy, A. B. and Balu, S. 2012. In vitro antioxidant and anti-inflammatory activity of Cocciniagrandis. Intl. Pharm. and Pharma. Sci. 4, 239-242.

24. Bhadauria, P., Arora, B., Vimal, B. and Kulshrestha, A. 2012. In vitro antioxidant activity of Cocciniagrandis root extracts. Indo Global J. Pharma. Sci. 2, 230-238.

25. Hasan, S. R., Jamila, M., Majumder, M. M., Akter, R., Hossain, M. M., Mazumder, M. E. and Rahman, S. 2009. Analgesic and antioxidant activity of the hydromethanolic extract of Mikaniascandens (L.) Willd. leaves. Amer. J. Pharmacol. and Toxicol. 4, 1-7. 